\title{
Aprender con otros sentidos: estrategias para la atención de alumnos con deficiencia visual
}

\section{Learning with Other Senses: Strategies Aimed for Students with Visual Disability}

\author{
Quelen Silveira Coden*1 \\ quelencoden@yahoo.com.br \\ Nilson Marcos Dias Garcia** \\ nilson@utfpr.edu.br \\ * Universidade Federal do Paraná, Brasil \\ ** Universidade Tecnológica Federal do Paraná, Brasil \\ y Universidade Federal do Paraná, Brasil
}

\section{Resumen:}

Tomando como base la experiencia desarrollada en una Sala de Recursos de la Red Pública de Enseñanza de Curitiba, en la Provincia de Paraná, Brasil, que atiende a alumnos con deficiencia visual, relata y analiza los resultados de la investigación que se hizo, bajo el punto de vista de estos alumnos y de sus profesores, los materiales didácticos, las actividades evaluadoras, el proceso de enseñanza-aprendizaje y la organización del contenido que posibiliten a los alumnos con deficiencia visual la apropiación del conocimiento de los contenidos de las disciplinas de las áreas de la Ciencia de la Naturaleza y de la Matemática.

Palabras clave:

Deficiencia visual; recursos didácticos para los ciegos; la enseñanza-aprendizaje de los ciegos; trabajo de colaboración; producción de recursos didácticos.

\begin{abstract}
:
Based on an experience developed with visually impaired students in a Resource Room of the Public Education System in Curitiba, in the State of Paraná, Brazil, this study analyzes the point of view of these students and their teachers, the didactic materials, the assessment activities, the teaching-learning process and the organization of contents that make it possible for students with visual deficiency to acquire knowledge of the contents in disciplines of the areas of Natural Sciences and Mathematics.
\end{abstract}

\section{Key words:}

Visual disability; didactic resources for blind people; teaching-learning processes of blind people; collaborative work; didactic resources design.

1 Dirección para correspondencia (correspondence address):

Quelen Silveira Coden. Rua Castro Alves, 99, apto 110, Batel. Cep: 80240-270 Curitiba/Paraná (Brasil). 
Aprender con otros sentidos: estrategias para la atención de alumnos con deficiencia visual

Quelen Silveira Coden y Nilson Marcos Dias Garcia

\section{Résumé:}

En se basant sur l'expérience développée dans une salle de Ressources du Réseau Publique de l'Enseignement de Curitiba, dans l'état de Paraná, au Brésil, qui assiste des élèves avec insuffisance visuelle, rapporte et analyse des résultats de la recherche réalisée, sous le point de vue de ces élèves et de leurs professeurs, les matériels didactiques, les activités d'évaluation, le procès d'enseignement-apprentissage et l'organisation de contenus qui rendent possible à des élèves avec insuffisance visuelle l'appropriation de connaissance des contenus des disciplines des secteur de Sciences de la Nature et de Mathématiques.

Mots clés:

Déficience visuelle; ressources didactiques pour aveugles; enseignement-apprentissage d'aveugles; travail collaboratif; production de ressources didactiques.

Fecha de recepción: 16-5-2017

Fecha de aceptación: 20-9-2017

\section{El concepto de la deficiencia y la inclusión de alumnos ciegos}

Acorde a Convención de Guatemala, ratificada por el gobierno brasileño a través del Decreto $N^{0}$ 3.956, de octubre de 2001, la deficiencia fue definida como "una restricción física, mental o sensorial, de naturaleza permanente o transitoria, la cual limita la capacidad de ejercer una o más actividades esenciales a la vida diaria, causada o agravada por el ambiente económico y social" (Brasil, 2001, p. 01), que puede presentarse de forma congénita o adquirida.

Esta conceptualización se ha mostrado más inclusiva, pues dependiendo de cómo se caracterice esta deficiencia, se definen también los espacios que estas personas ocupan en la sociedad, superando el concepto de deficiencia que remetía a las características de innatismo y estabilidad y a las pruebas elaboradas con la finalidad de clasificar a las personas como normales y deficientes en medio así como el surgimiento de las escuelas especiales como alternativa para la atención educativa de estos alumnos. (Coll, 2004, p. 15)

Ya en 1940 y 1950 los estudios habían comenzado a tener en cuenta las influencias sociales y culturales como responsables también por un funcionamiento intelectual deficitario y a partir de 1960 ocurren cambios significativos y la deficiencia pasa a ser entendida bajo el prisma de una perspectiva educacional, dando lugar al surgimiento de la terminología "necesidades educativas especiales". (Coll, 2004).

Esta nueva visión prevé recursos y profesores especializados, haciendo posible que los alumnos con deficiencia estén atendidos, preferente- 
mente, en la Enseñanza Regular. Estas cuestiones ya habían sido discutidas durante la Conferencia Mundial sobre las Necesidades Educativas Especiales, y cuyo documento final, que fue Ilamado "Declaración de Salamanca" proclama que:

- todo niño tiene el derecho fundamental a la educación, y le debe ser garantizada la oportunidad de alcanzar y de mantener el nivel adecuado de aprendizaje,

- todo niño posee características, intereses, capacidades y necesidades de aprendizaje que son únicas,

- los sistemas educativos tendrían que ser asignados y los programas educativos tendrían que ser implementados en el sentido de tener en cuenta la extensa diversidad de tales características y necesidades,

- aquellos con necesidades educativas especiales deben tener acceso a la escuela regular, que debería acomodarlos dentro una Pedagogía centrada en el niño, capaz de satisfacer a tales necesidades,

- las escuelas regulares que posean tal orientación inclusiva constituyen los medios más eficientes para combatir a las actitudes discriminatorias creándose comunidades acogedoras, construyendo a una sociedad inclusiva y alcanzando la educación para todos; además, tales escuelas proporcionan una educación efectiva a la mayoría de los niños y mejoran la eficacia y, en última instancia, el costo de la eficacia de todo el sistema educativo. (Brasil, 1994, p. 1)

Esta declaración produjo efecto en las legislaciones educativas de los países signatarios. En Brasil esto ocorrió en la ley de Directrices y Bases de la Educación Nacional (LDB) - Ley 9.394, de 1996, que en su artículo 59 garantiza organización escolar específica para atender las necesidades de los alumnos con necesidades especiales.

Para hacer frente a este desafío, en 2008, el Ministerio de la Educación del Brasil - MEC, a través del decreto $\mathrm{n}^{0}$ 6.571, ha comenzado a brindar el soporte técnico y financiero para la implantación de las Salas de Recursos Multifuncionales en el país². A su vez, la Secretaría de Educación de la Provincia del Paraná, a través de la Instrucción Normativa $n^{0} 06$, de 2016 ha establecido que

2 Las Salas de Recursos Multifuncionales son "ambientes dotados con equipamientos, mobiliarios y materiales didácticos y pedagógicos para la oferta de la atención educativa especializada" (Brasil, 2010, 5), siendo, por lo tanto, el espacio físico destinado a la Atención Educativa Especializada. 
Aprender con otros sentidos: estrategias para la atención de alumnos con deficiencia visual

Quelen Silveira Coden y Nilson Marcos Dias Garcia

La atención estará disponible a los estudiantes ciegos, de baja visión o de otros acometimientos visuales, a partir de los 06 (seis) años de edad, registrados regularmente en las instituciones de enseñanza que ofrecen Educación Primaria (años finales) o Educación Secundaria, atendidas en de la red pública. ... El número máximo para cada Sala de Recursos Multifuncionales es de 10 (diez) estudiantes con atención por cronograma. ${ }^{3}$

La atención en las Salas de Recursos debe ser realizada por un profesional que, más allá de las atribuciones citadas arriba, deba desarrollar el trabajo de soporte pedagógico, producción de materiales didácticos y pedagógicos accesibles y orientación a los profesores de la Educación Regular que tengan alumnos deficientes visuales en sus aulas.

Lo avala en ese sentido la Nota Técnica n ${ }^{0}$ 11/2010 de la Secretaría de Educación Especial del Ministerio da la Educación, que presenta orientaciones para la institucionalización de la oferta del Servicio Educativo Especializado en Salas de Recursos Multifuncionales, implantadas en las escuelas regulares. En este documento se resalta la importancia del cambio de concepción pedagógica, de formación docente y de gestión educativa para la transformación de las estructuras educativas y la implementación de la educación para todos.

Una de las Salas de Recursos creadas para la atención de deficientes visuales en la Provincia del Paraná está ubicada en la Escuela Pública Don Pedro II, en Curitiba, en la cual fue llevada a cabo la investigación relatada en este artículo.

\section{La investigación}

Según el entendimiento de la profesional que atiende a la Sala de Recursos objeto de nuestra investigación, que es una de las autoras del presente artículo, para que los alumnos reciban una atención satisfactoria, en la Sala de Recursos Multifuncionales así como en su aula regular, se hace

3 "Una persona tiene visión subnormal o baja visión cuando presenta 30\% o menos de visión en el mejor ojo, después de todos los procedimientos clínicos, quirúrgicos y corrección con anteojos comunes. Estas personas presentan dificultades en ver detalles en el dia a dia. Por ejemplo, ven las personas pero no reconocen los rasgos; los niños ven la pizarra, pero, no identifican las palabras; en la parada de colectivos, no reconocen los carteles." www. fundacaodorina.org.br 
necesario el soporte de otros profesionales, con conocimiento distinguido. En función de esta necesidad, han sido establecidos trabajos en conjunto con instituciones educativas, recibiendo alumnos de graduación que son asistidos en sus estudios académicos y por otra parte asisten a la producción de materiales adaptados y proyectos de extensión en que los profesores de la educación regular reciben la formación continuada relativa a las especificidades de la atención de alumnos con deficiencia visual.

Con el objetivo de enriquecer las actividades desarrolladas en esta Sala de Recursos Multifuncionales, metodologías de enseñanza y aprendizaje, recursos y herramientas han sido investigadas, para que hagan posible a los alumnos con deficiencia visual que frecuentan aulas regulares la adquisición del conocimiento de los contenidos de las disciplinas, puesto que "toda persona con deficiencia tiene derecho a la igualdad de oportunidades con las demás personas y no sufrirá ninguna especie de discriminación". (Brasil, 2015)

El trabajo empírico ha ocurrido en el período comprendido entre noviembre de 2016 y marzo de 2017. Como estrategia de investigación se han Ilevado a cabo entrevistas semiestructuradas con cuatro estudiantes ciegos de tres escuelas públicas y cuatro profesores que habían actuado con tres de estos alumnos ciegos en dos de estas escuelas, que ya habían desarrollado actividades junto a la Sala de Recursos Multifuncionales de la Escuela Pública Don Pedro II, donde actúa una de las autoras.

\section{Los sujetos de la investigación}

Los profesores y los alumnos que han colaborado con este estudio serán identificados por los códigos: Profesor 4, Profesor 6, Profesor 7, Profesor 8, Alumno 1, Alumno 2, Alumno 3 y Alumno 4.

El profesor 4 se ha graduado en Nutrición con complementación para ministrar clases de Química y Especialización en Educación para Jóvenes y Adultos y Utilización de Tecnologías en el Aula. Hace 18 años que actúa en escuelas públicas. En su formación inicial no ha cursado disciplinas que discutieran la cuestión de la deficiencia y de la inclusión escolar.

El profesor 6 ha cursado la Licenciatura, maestría y doctorado en Física, disciplina que enseña hace 10 años en escuelas públicas. En su 
formación inicial no ha tenido disciplinas que tuviesen en cuenta la cuestión de la deficiencia y de la inclusión escolar.

El profesor 7 ha cursado Licenciatura en Química y especialización en Metodología de la Educación en Química, disciplina con la cual viene trabajando en escuelas públicas hace 10 años. En su formación inicial no ha tenido disciplinas o conferencias que tuviesen en cuenta la deficiencia y la inclusión escolar.

El profesor 8 se ha graduado en Administración de Empresas con Especialización en Marketing Empresarial. Ha actuado por veinte años como administrador y antes de jubilarse se ha habilitado profesor de Matemática, a través de un curso de formación pedagógica. En este curso, más reciente que los de los otros profesores participantes, había una disciplina que abordaba los aspectos de la legislación relacionada a la inclusión escolar. Ministra la disciplina de Matemática hace cuatro años.

El alumno 1 tiene 16 años, de sexo masculino y tiene ceguera congénita. Entiende la deficiencia como un pequeño problema que puede o no ser solucionado, dependiendo del individuo mismo. Está cursando el tercer año de la Secundaria en una escuela Pública de la zona central de Curitiba que posee Sala de Recursos y recibe soporte pedagógico en una institución especializada en deficiencia visual, además de frecuentar el proyecto de Matemática en la Sala de Recursos de otra institución.

El alumno 2 tiene 19 años, es del sexo femenino y su ceguera también es congénita. Considera que la deficiencia es solamente una limitación, que es posible tener una vida normal, hacer cosas como cualquier otra persona, pero con algunas cosas que quizás tengan que ser distinguidas o adaptadas. Cursa el tercer año de la Secundaria en una escuela que no posee Sala de Recursos, ubicada en la zona periférica de Curitiba. Frecuenta una institución especializada en deficiencia visual para recibir el soporte pedagógico.

El alumno 3 tiene 16 años, es del sexo femenino y su deficiencia visual ha sido adquirida. Entiende la deficiencia como una limitación un poco más grande, donde la persona necesita de más ayuda, pero no que sea diferente a los demás. Cree que puede hacer todo que los otros hacen, pero de una forma diferente. Frecuenta una escuela de la zona central de Curitiba, donde cursa el primer año de la Secundaria. En su escuela hay Sala de Recursos y además participa de proyectos y recibe el soporte pedagógico en la Sala de Recursos de otra escuela.

El alumno 4 tiene 18 años, es del sexo masculino y tiene ceguera con- 
génita. Considera la deficiencia como un límite que quizás sea posible superar. Está cursando el tercer año de la Secundaria en una escuela de la periferia de Curitiba. Su escuela posee Sala de Recursos y en ella él recibe atención educativa especializada.

\section{Los resultados}

El análisis de las entrevistas si ha apoyado en tres categorías:

- "Material Didáctico", que busca explicitar los materiales didácti$\cos ^{4}$ que los profesores utilizan en sus clases y que están disponibles para los alumnos ciegos;

- "Actividades Evaluativas", que tienen por objetivo profundizar el sentido de la evaluación para el profesor y para el alumno, y cómo ella puede ser un factor favorable para la inclusión o la exclusión del alumno ciego;

- "Proceso de enseñanza aprendizaje", que comprende la explicitación de la metodología de la educación utilizada, de las expectativas de aprendizaje y del concepto de deficiencia expreso por los participantes, entendiendo que la forma en cómo cada individuo entiende la deficiencia influye significativamente en este proceso y organización de los contenidos.

\section{Material didáctico}

Para seguir el contenido en aula los alumnos tienen también el derecho de poseer los libros didácticos, garantizado por el Programa Nacional del Libro Didáctico - PNLD 5 . En el ámbito de este Programa, el Ministerio de la Educación - MEC ha adoptado mecanismos para garantizar la accesibilidad a los materiales didácticos y ha lanzado el Mecdaisy, programa que posibilita la generación de libros digitales hablados y su reproducción en audio, grabado o sintetizado.

4 Por materiales didácticos se compreende libro didáctico (impreso o digital), juegos, recursos pedagógicos y tecnologías

5 El Programa Nacional del Libro Didáctico - PNLD, es un programa gubernamental que tiene como objetivo evaluar, adquirir y distribuir a los alumnos y a los profesores de las escuelas públicas brasileñas los libros didácticos y las colecciones de obras literarias, obras complementarias y diccionarios. 
Aprender con otros sentidos: estrategias para la atención de alumnos con deficiencia visual

Quelen Silveira Coden y Nilson Marcos Dias Garcia

Este estándar presenta la facilidad de la navegación por el texto, permitiendo la reproducción sincronizada de trechos seleccionados, el retroceso y el avance de párrafos y la búsqueda de secciones o de capítulos. También posibilita adjuntar notas a los archivos del libro, así como la lectura en caracteres extendidos. Todo texto es indexado, facilitando, así, la navegación a través de índices o de búsquedas rápidas. (Brasil, 2013, p. 01).

Sobre los materiales que los alumnos tenían a disposición en el aula, sin embargo, tanto los alumnos cuánto los profesores han contestado que en la mayoría de las situaciones no había todo el material didáctico necesario y en una situación ha quedado clara la inexistencia de cualquier material para el acompañamiento de las clases.

El profesor 7 reportó que él poco utilizaba el libro didáctico, sólo para algunas actividades y como utilizaba mucho la pizarra, organizó un material de apuntes con la misma información y solicitó que el profesor de la Sala de Recursos hiciera la impresión en braille, de manera que el alumno tuviera acceso a toda la información escrita en la pizarra. También respondió que nunca había tenido la experiencia de trabajar con ciegos y contó con la ayuda del profesor de la Sala de Recursos. Según él,

Nosotros intentamos desarrollar un modelo molecular para que pudiera tener aquella noción espacial de las moléculas, como que los átomos se organizaban. Entonces utilizamos pelotas de madera, como las que se utilizan para artesanías y nosotros trabajamos con ese material y con canudos para representar las conexiones entre los átomos. Entonces el tenía este material para tocar, para entender esta noción espacial y cuando era una cierta cosa escrita, una cierta representación yo buscaba traer listo utilizando esas tintas de alto relieve. (Profesor 7)

En la disciplina de Matemática el profesor 8 también tuvo que organizarse, por lo que el alumno ciego no recibió el libro didáctico, ni en la versión braille y ni en la versión de Mecdaisy. De modo que tuviera acceso a los registros de los contenidos, el profesor hacia los resúmenes y los dictaba y produjo materiales concretos e hizo uso de la tecnología asistiva como el Multiplano. 


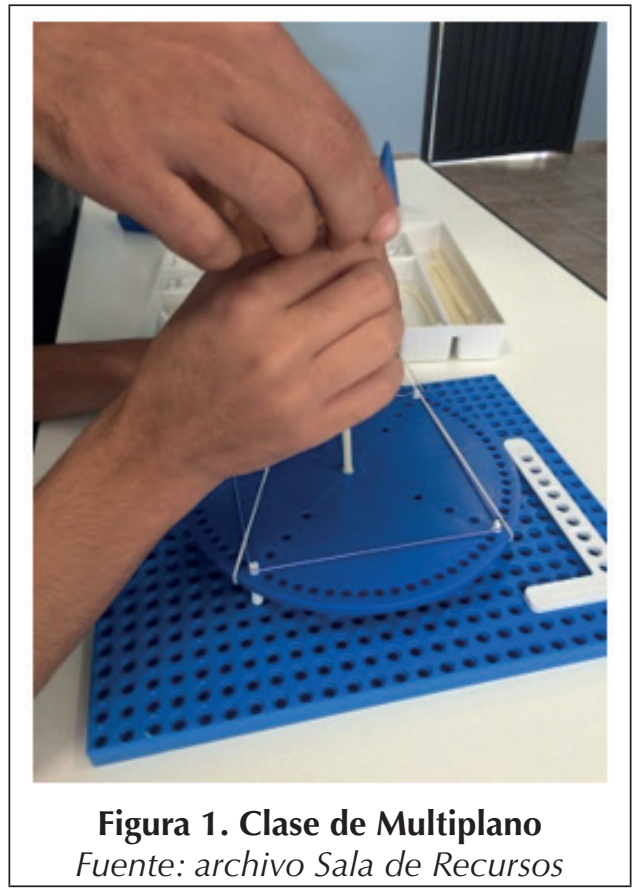

Se ha percibido que el alumno que conoce esta tecnología asistiva en la Sala de Recursos comienza a utilizarla en el aula, ampliando su acceso al conocimiento, disminuyendo las barreras para alcanzar el entendimiento de los contenidos y sintiéndose más incluido. En lo que se refiere a la accesibilidad, Diogo e Silva (2013) afirman que: "de forma amplia, la accesibilidad lleva a la inclusión, independiente del contexto a que se relaciona, tecnológico, educativo o comunicacional. Básicamente, ser accesible significa que las barreras entre el usuario y la información fueron eliminadas o reducidas." (p. 06)

La herramienta Multiplano viene al encuentro de esta perspectiva, pues posibilita la autonomía para la realización de actividades de cálculos y corrobora con lo qué Camargo dice (2012): "la inversión en el desarrollo de materiales que proporcione las condiciones es necesaria de modo que este discente, de forma simultánea, registre, observe lo que registra y razone". (p. 260)

La alumna 2 fue más perjudicada en términos de material didáctico, aunque haya recibido los libros en el formato Mecdaisy, no aprendió a utilizar software para abrir y para tener acceso al contenido. Ella relata que la única disciplina que tuvo un material diferenciado fue Química, 
Aprender con otros sentidos: estrategias para la atención de alumnos con deficiencia visual

Quelen Silveira Coden y Nilson Marcos Dias Garcia

donde la profesora demostró voluntad en adaptar los materiales, teniendo una experiencia positiva al principio del año escolar, pero no continuó con la práctica.

\section{Actividades Evaluativas}

La evaluación está inserta en el proceso de enseñanza-aprendizaje y es una forma de mensurar el conocimiento de los alumnos, así como identificar formas para mediar e intervenir en el aprendizaje de éstos. Las distintas concepciones acerca de la evaluación definen prácticas e instrumentos a ser utilizados. Los estudios bibliográficos señalan tres tipos distintos de evaluación: clasificatoria, diagnóstica y emancipatoria.

Sobre la evaluación clasificatoria Meneguel y Kreish (2009) afirman que en esta "no hay proceso de reconstrucción del saber, sino, sí, la preocupación con avanzar en el contenido previsto en las unidades del libro." Y completam

una vez que se lleva a cabo solamente en el final del proceso de aprendizaje, teniendo el poder de impedir la trayectoria escolar del estudiante, también se dice que la evaluación clasificatoria posee el carácter frenador y que él trae daños a esto." (p.9822)

Este tipo de evaluación se preocupa en atribuir una nota o concepto al alumno y no valora lo qué y cómo él aprende. La evaluación diagnóstica permite evaluar las dificultades y las potencialidades del alumno. Según Penna Firme (1994) en Meneguel y Kreish (2009),

Este concepto se basa en la idea de que, para el profesor, la atención al desempeño del estudiante es elemento primordial a la práctica pedagógica; o sea, corresponde al educador desarrollar estrategias que le permitan conocer los errores y aciertos del alumno con el fin de promover su objetivo cognitivo. (p. 9823)

Ya la evaluación en la perspectiva emancipatoria es procesal, sus instrumentos son variados y continuos y tienen como propósito reconstruir y mejorar el saber de los alumnos, conociendo sus condiciones de aprendizaje y sirviendo como base para la proposición pedagógica del trabajo. 
Al analizar el discurso de los profesores puede ser evidenciado la presencia de los tres tipos de evaluación.

El profesor 8 relata que él aplica la evaluación de Matemática igual para todos los alumnos, y lo único que distingue es el formato en braille para el alumno ciego. Así como el profesor 4, en la disciplina de Química, que aplica la evaluación igual para los alumnos videntes y los alumnos ciegos, no obstante hace uso de la tecnología asistiva para auxiliar a los alumnos en lo que se refiere al tiempo, pues la lectura de la prueba en braille demanda un tiempo adicional. De esta manera, opta por digitar las cuestiones de la prueba y a guardarlas en formato txt. En el momento de la prueba envía para el correo electrónico de los alumnos, que poseen la computadora y tienen acceso a la Internet en el aula. Ellos contestan a las preguntas en archivo de texto y hacen la impresión al final de la evaluación. En un determinado momento de la charla esta profesora dijo que en años anteriores trabajaba de manera muy distinta y después de tener el endoso de la Sala de Recursos y las orientaciones necesarias ella se dio cuenta que tendría que resignificar su práctica. En su opinión, en las experiencias anteriores, no podría evaluar los alumnos ciegos de la misma manera que los demás.

Si yo no logré explicar de una forma que consiguiera alcanzar al alumno sería muy injusto exigir de la misma forma que exigía de los demás alumnos, entonces nosotros terminábamos pecando, nosotros sabíamos que el alumno no aprendía lo que él tenía que haber aprendido pero como nosotros iríamos desaprobar un alumno, retener a un alumno si nosotros no habíamos podido enseñar, así si yo no logro enseñar como que voy a exigir del alumno que sepa hacer una evaluación, hacer un trabajo, y así en adelante. Entonces nosotros terminamos trabajando mucho con textos, entonces de repente en segundo año que es un grupo que trabajo con muchos cálculos, yo trabajaba con textos, porque no podía llegar hasta el alumno, ¿cómo yo iría a exigirle esto? [...] No se hablaba, pero era aquel acuerdo medio tácito yo te lo facilito, tu haces el mínimo, entonces apruebas y nosotros continuamos muy bien, yo finjo que está todo bien, tu finges que está todo bien. (Profesor 4)

Se percibe cuan es importante el conocimiento acerca de las potencialidades de los alumnos con deficiencia y el trabajo de colaboración junto al profesor de la Sala de Recursos de modo que ocurra un cambio en la práctica pedagógica en pro del aprendizaje. La profesora pasó 
Aprender con otros sentidos: estrategias para la atención de alumnos con deficiencia visual

Quelen Silveira Coden y Nilson Marcos Dias Garcia

de una práctica evaluativa clasificatoria, donde cumplía con la legislación, recibiendo el alumno y asistiendo de modo que lo promovieran, no obstante sin tener éxito en el proceso de enseñanza, a una práctica emancipatoria, donde ella entiende las especificidades de la persona con deficiencia visual y utiliza los recursos y las tecnologías necesarios para evaluar sus conocimientos.

Ya el profesor 7, además del uso de la computadora, percibió la necesidad de adaptar imágenes de modo que el alumno tuviera acceso a la misma evaluación que su grupo.

Como yo utilizaba mucha representación de imagen, lo hacía en el relieve para él. La mayoría de las pruebas, la primera no porque seguía siendo una experiencia, pero a partir de la segunda prueba, una vez que yo apliqué al grupo, yo traía ya guardado en txt, guardaba el archivo de la parte escrita en la computadora del alumno, él escuchaba a través de la computadora y cuando le daba allí una indicación de la imagen él iba para la hoja que yo había preparado con la imagen en relieve. (Profesor 7)

Para el profesor 6, que ministra la disciplina de Física, tan pronto inició el trabajo en el grupo con el alumno ciego era necesario hacer la evaluación diferenciada.

Al principio, confieso, que allá en los dos primeros bimestres, primer año, yo no tenía mucho esta noción. Entonces yo preparaba para él más conceptual, pero un día, en una charla con el profesor del Sala de Recursos él dijo tu puedes hacer los cálculos normalmente porque hay todo un estándar de escrita en braille que él puede seguir. Solo tiene que darle mayor tiempo, que él tiene que leer. (Profesor 6)

Los alumnos también comentaron sobre las evaluaciones. El alumno 2 relata que raras veces hizo alguna evaluación formal como los demás compañeros y que le gustaría hacer cálculos y pruebas como los colegas videntes, pero le solicitaban solamente trabajos de investigación en Internet. Tuvo expectativas positivas con relación a la disciplina de Química, no obstante observó problemas posteriores.

Hasta el comienzo del año, mi profesora hasta se esforzó para ayudarme. Ella intentó adaptarme algo. Después, de la nada así, ella paró simplemente, 
Quelen Silveira Coden y Nilson Marcos Dias Garcia

dijo que yo era inteligente, que no necesitaba mucha teoría, que me iba a dar la nota, que ella iba a ver la evaluación, ver... ver,..., ver..., dicen siempre que van a ver, solo ver las cosas y al final de cuentas no me dijo nada más y probablemente sé que me dio la nota sin merecerla. Porque lo máximo que aprendí en Química. ¿Qué fue? Estructuras, por fin... cosas que ella intentó adaptar y más adelante desistió. (Alumno 2)

Para el Alumno 1 el problema también se refiere a la forma como se aplican las evaluaciones. El relata que en la disciplina de Biología siempre ha hecho prueba oral, y en el ambiente de la Sala de Recursos, hecho este que lo incomodaba, por separarlo de su grupo debido a su deficiencia visual. En cuanto a las evaluaciones de Física, siempre fueron en el formato braille e iguales a las de su grupo, no obstante nunca habían llegado en el mismo día.

Yo tuve clases con la misma profesora por dos años y solamente una vez ha logrado entregar la prueba en el día, ¿se entiende? Por esta razón me quejé que retrasa. Pero recuerdo que en el primer bimestre la prueba estaba correcta. Es el mismo contenido y viene en braille. (Alumno 1)

En relación a la disciplina de Matemática, el alumno 1 señala que las pruebas están en formato braille y con los dibujos adaptados, por lo cual él necesita de la ayuda de algún colega o profesor para entender el dibujo.

Generalmente le pido a alguien que me explique. [...] Porque tu no sabes donde está cada medida. ¿no?. A veces tu ordenas el dibujo de una manera equivocada y entonces cambia totalmente. Tú no sabes lo que estas dibujando ali, lo que quieres transmitir el dibujo. (Alumno 2)

En relación a las imágenes, es importante marcar que con solamente estar en relieve no es suficiente, pues primero el alumno necesita aprender el significado de la imagen y esto solo es posible con la mediación de alguien, principalmente si se trata de ciegos congénitos, que no poseen memorias visuales. Para ellos las líneas y relieves no significan nada si no son enseñados a analizar y relacionar con conceptos. Es necesario también seguir códigos que se encajen tanto para los videntes como para los ciegos, como el dibujo universal, según lo explicado por Camargo (2017): 
Aprender con otros sentidos: estrategias para la atención de alumnos con deficiencia visual

Quelen Silveira Coden y Nilson Marcos Dias Garcia

La estructura propuesta por el dibujo universal presupone la diversidad y el trabajo con identidad y diferencia en su constitución. La metodología, proceso de comunicación y el material de instrucción, elementos propios de los principios de la diversidad, identidad y diferencia y no de la homogeneidad y de los espacios homogeneizantes, estos últimos productos de la construcción social. (p.4)

Para el alumno 4 las evaluaciones siempre tuvieron el mismo contenido y cantidad de preguntas que los demás compañeros y estaban disponibles en braille. Él relata que en algunas ocasiones solicitaba la prueba de forma oral y que era atendido rápidamente.

$\mathrm{Al}$ analizar los relatos de los entrevistados es posible percibir que algunos profesores, aún sin el conocimiento anterior acerca de la deficiencia, buscaron formas diferenciadas de modo que el alumno pudiese ser evaluado, respetando sus condiciones. En este sentido Christofari y Baptista (2012) ponderan:

Así, cuando discutimos el proceso de evaluación como una estrategia que se puede construir de acuerdo con la perspectiva de inclusión escolar la intención es convocar a una mirada distinta para esta práctica de un modo general. En este proceso, dos tipos de enlace llegan a ser imprescindibles: con el contexto en el cual se produce la evaluación, pues cualquier desempeño a ser evaluado es histórico, singular y se produce en determinadas condiciones; además este desempeño no se refiere solamente al sujeto evaluado, sino expresa, en su configuración, las creencias y las suposiciones de aquel que evalúa. La evaluación, concebida como dispositivo, nos expone, pues habla de nosotros y, contemporáneamente, nos hace hablar. (p. 393)

\section{Proceso Enseñanza-Aprendizaje}

Con respecto a eso, el cuestionamiento fue dirigido acerca de como es ministrar clases en grupo con alumnos ciegos, si hay necesidad de hacer un planeamiento distinto y si hay alguna dificultad.

Para el profesor 6 el alumno ciego tiene condiciones de seguir la clase, así como los colegas videntes. Lo que lo diferencia es que él no tiene visión, pero es más sensible en el tato y la audición.

En este punto es importante marcar que existen muchos mitos acerca 
del aprendizaje de los alumnos con deficiencia visual, y es común creer el en superdesarrollo auditivo y táctil, atribuyendo al tato la posibilidad de coger las mismas informaciones que la visión. Según Vigotski (1997) el tacto y la audición nunca harán a un ciego ver (p.5), no obstante en la ausencia del sentido de la visión es necesario utilizar los sentidos restantes: tacto, olfato, paladar y audición para coger las informaciones del medio. Por medio de la intermediación de otras personas es que estas informaciones van a recibir significados y se transforman en aprendizaje.

Todos los profesores afirman que el planeamiento de la clase es igual, independientemente de tener alumno ciego en el grupo o no. Qué distingue es la necesidad de anticipar la organización de la clase para tener tiempo hábil de solicitar al profesor de la Sala de Recursos los materiales adaptados y los recursos necesarios, así como la forma de exponer el contenido.

una cosa que aprendí mucho era cuando hacia figuras en la pizarra, no era suficiente solo hacer la figura, tenía que pensar como describirla. Tenía esos pequeños detalles que tenía que recordar de como, él no ve, yo le iba a exponer esto. (Profesor 6 - Física)

tenía mucho cuidado durante la clase con la manera de hablar. Fue algo que controlé mucho, ¿no? entonces: ¡mira aquí! ¿Cuántos átomos tienen aquí? Entonces en su aula yo cambiaba la manera de presentar el contenido, buscaba utilizar: aquí en la pizarra tenemos una molécula con siete carbones, de el segundo al tercer carbón tengo una ligación doble, para que él pudiese visualizar ¿no?. (Profesor 7 - Química)

Es posible percibir que los profesores tuvieron la preocupación en modificar su forma de exponer los contenidos, generalmente con mucho uso de la pizarra y de imágenes, para atender a todos los alumnos simultáneamente. No descartaron los recursos visuales, necesarios a la mayoría del grupo, pero pensaron formas para que los alumnos ciegos pudiesen construir sus imágenes mentales por medio del habla y de utilización de recursos.

Sin embargo, es importante marcar que, sin que haya una preocupación con la construcción de imágenes mentales, los alumnos ciegos no establecen relación entre los códigos auditivos (profesor hablando) asociados a los códigos visuales (dibujos, esquemas en la pizarra), como aseverado por Camargo (2016): 
Aprender con otros sentidos: estrategias para la atención de alumnos con deficiencia visual

Quelen Silveira Coden y Nilson Marcos Dias Garcia

Una condición fundamental para la participación de discentes con deficiencia visual en clases de Física dice respecto al desarmar de la estructura empírica audio-visual interdependiente. Esta estructura se puede reconocer fácilmente en los perfiles comunicativos del tipo esto más esto es igual a esto (profesor que demuestra la resolución de la ecuación); noten las características de este gráfico... (el profesor señala con las manos características del gráfico escrito o proyectado); acorde a lo qué nos informa esta tabla ... (señala características descritas en la tabla); cuando la fuerza aumenta del gráfico, observen para donde va el desplazamiento (indica las características gráficas) (p. 42)

Además, para que el proceso de inclusión educativa del alumno con deficiencia visual tenga éxito, según Mantoan (2004), el profesor necesita reconocerlo y asumirlo como diferente.

$\mathrm{Ni}$ todas las diferencias necesariamente inferiorizan las personas. Hay diferencias y hay igualdades: ni todo debe ser igual y ni todo debe ser diferente. Entonces, como concluye Santos es necesario que tengamos el derecho de ser diferentes, cuando la igualdad nos descaracteriza, y el derecho de ser iguales, cuando la diferencia nos inferioriza. (p. 39)

El discurso del profesor 8 consolida el derecho del alumno de ser diferente: "sin recursos hoy es muy difícil enseñar a un ciego, el recurso tiza y pizarra solas es muy poco para enseñar a alguien que es diferente en aquel momento".

Sobre el proceso enseñanza-aprendizaje los alumnos relataron qué factores consideran primordiales para el desarrollo académico. En común ellos prefieren que los profesores hagan uso del libro didáctico del PNLD, material que generalmente pueden tener acceso, y para estudiar en casa utilizan Internet donde buscan vídeo-clases y apuntes digitales.

El libro didáctico en el formato de Mecdaisy, sin embargo, presenta potencialidades e imperfecciones. Facilita el acceso a la información por traer las descripciones de todas las imágenes. Pero dificulta, principalmente en las disciplinas que pueden presentar expresiones matemáticas o fórmulas, por hacer la lectura de caracteres con el código de la ASCII

6 ASCII es una sigla para "American Standard Code for Information Interchange" (Código Padrón Norte-americano para Intercambio de Informaciones). O ASCII es un código numérico que representa los caracteres, utilizando una escala decimal de 0 a 127. Esos números decimales son entonces convertidos por la computadora para 
no reconociendo simbologías y dejando la lectura incomprensible en estas situaciones. Por estas particularidades, es más usual que el alumno utilice los libros de Matemática, Física y Química impreso en braille.

Como ejemplo de esta situación donde él es un dificultador, se reporta la actividad de una profesora que estaba trabajando Movimiento Uniforme, un tema de Física, como se muestra en la Figura 2. La alumna ciega tenía a su disposición el mismo en el formato digital Mecdaisy. Sin embargo, como la lectura del software de Mecdaisy presenta una serie de informaciones incomprensibles en el contexto, al tratarse de cálculos y de simbología matemática se optó por formatear y hacer la impresión de este material en braille.

Por otro lado, cuando en el libro didáctico impreso se refiere a imágenes de situaciones cotidianas, la mejor opción fue disponibilizar el material en Mecdaisy, pues permite mayor agilidad en la lectura de los textos y se describen las imágenes que figuran en la página. (Figura 3)

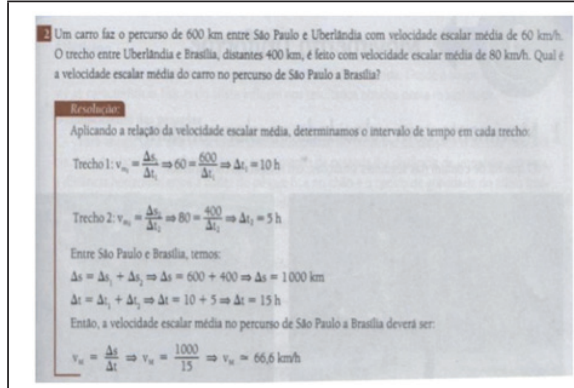

Figura 2. página del libro didáctico

Fuente: Archivo Sala de Recursos

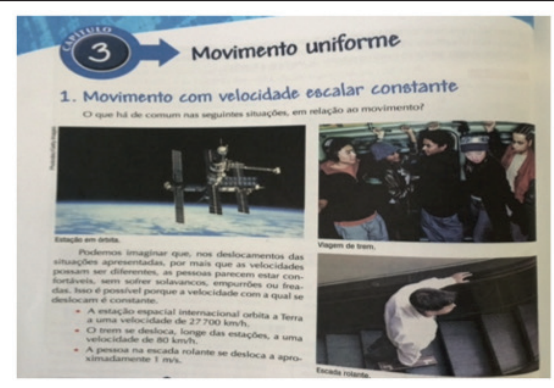

Figura 3. página del libro didáctico Fuente: Archivo Sala de Recursos

El alumno 3 cita como factor positivo el hecho de que algunos profesores envíen las notas de la clase por correo electrónico. Para Carvalho (2015) la computadora es un aliado del alumno ciego en la transposición de las barreras de accesibilidad y indica que "entre las herramientas del interfaz auditivo más utilizadas actualmente tenemos el NDVA, el JAWS, el VIRTUAL VISION, el ORCA y el Dosvox". (p. 22)

En la Sala de Recursos que fue usada como referencia para esta investigación, los alumnos atendidos utilizan más el NDVA (lector de panta-

códigos binarios y él procesa el comando. Cada una de las letras que tu digites ira corresponder a uno de esos códigos. (http://www.tecmundo.com.br/imagem/1518-oque-e-codigo-ascii.htm - acceso en octubre de 2016) 
Aprender con otros sentidos: estrategias para la atención de alumnos con deficiencia visual

Quelen Silveira Coden y Nilson Marcos Dias Garcia

Ila) y el Dosvox, ambos softwares libres. En las imágenes que siguen una alumna está resolviendo una ecuación de $2^{0}$ grado en la computadora (Figura 4), utilizando la herramienta Edivox, y construyendo el gráfico de la misma en el multiplano (Figura 5). La combinación de los dos recursos permite que ella desarrolle el razonamiento, resuelva el problema, haga el registro del cálculo y del gráfico, ejecutando la tarea por completo.

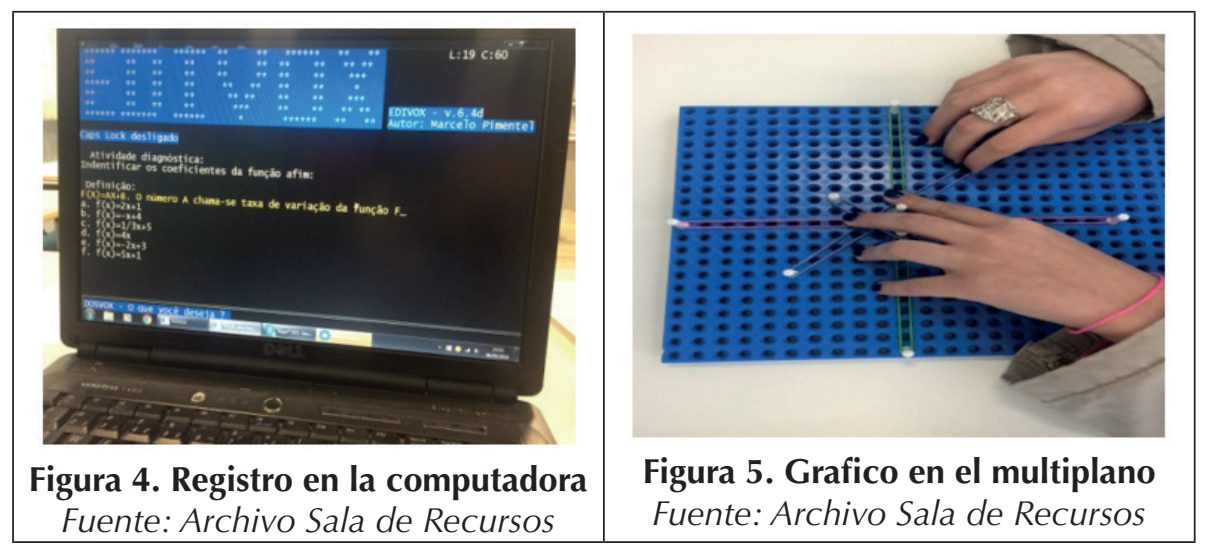

El Edivox, editor de texto del paquete Dosvox, permite que el alumno digite y escuche al mismo tiempo que está escribiendo. Como herramienta de registro, la computadora brinda mayor agilidad y autonomía.

En otras situaciones, donde aparecen gráficos e ilustraciones de fenómenos, es relevante presentar el tema a través de maquetas, para que el alumno pueda construir una imagen mental. Como ejemplo, citamos la situación del estudio de la temática electrización, apoyada en el funcionamiento de un electroscopio ${ }^{7}$. En el libro didáctico figuraba la imagen del electroscopio y toda la explicación estaba acorde con el movimiento de las láminas del mismo. Sin conocer al objeto sería difícil para el alumno comprender la acción. Para facilitar la construcción de la imagen mental del dispositivo y del significado del movimiento de las láminas, una maqueta fue producida, y manipulada por los alumnos. (Figuras 6 y 7$)$

7 El electroscopio es un dispositivo que permite verificar si un cuerpo está o no electrizado. La maqueta utilizada reproduce el electroscopio que es usualmente utilizado en las clases de Física, compuesto por una varilla metálica à la cual son colocadas dos hojas delgadas también metálicas que se abren o cierran acorde un material electrizado es aproximado o puesto en contacto con la varilla. 


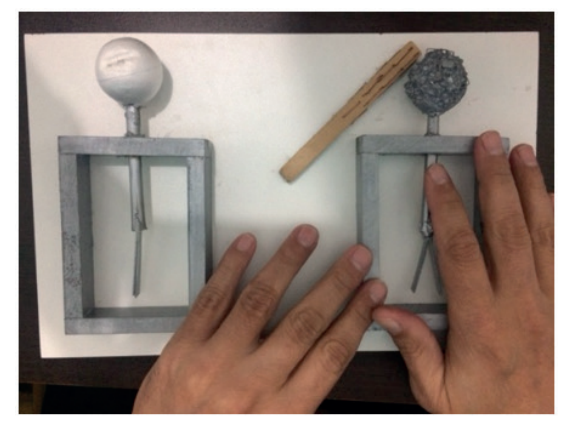

Figura 6. alumno utilizando maqueta del electroscopio

Fuente: Archivo Sala de Recursos

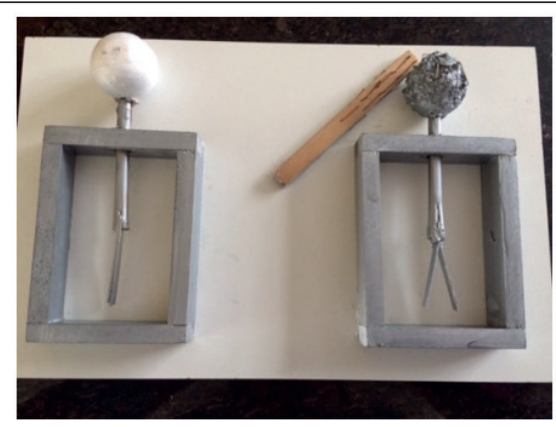

Figura 7. maqueta del electroscopio ${ }^{8}$ Fuente: Archivo Sala de Recursos

Sin embargo, es importante marcar que no siempre hay tiempo hábil para elaborar y para trabajar con los diversos materiales alternativos. Así, es necesario que los alumnos sean estimulados y se acostumbren a las descripciones de imágenes, de gráficos y de fenómenos.

A pesar de que todos afirman poseer carencia de algún material y de una alumna relatar no tener acceso al mínimo deseable - el libro didáctico, la comunicación entre los agentes implicados en el proceso fue considerada como factor primordial para el proceso de enseñanzaaprendizaje.

Yo espero accesibilidad, tener material adaptado, tener profesor interesado, inclusión en el aula, no ser considerada diferente de los demás, tener una buena comunicación entre el profesor, la dirección, el profesor del Sala de Recursos y yo. (Alumna 3)

Así, de acuerdo con Forgiarini (2012) "no basta incluir a las personas con deficiencia en la educación regular. Ocupar el mismo espacio que los dichos normales no significa ser aceptado y estar efectivamente incluido, pues las exclusiones suceden de forma tácita, así como también, explícitas". (p.57)

Ya el Alumno 4, el único que relató sentirse parte del grupo, señala como factor positivo la relación con los compañeros y el respecto que los mismos tenían con sus especificidades. Él comenta que en las clases

8 Maqueta producida por José Abilio de Souza Penna, Profesor de Física, jubilado por la Pontifica Universidad Católica del Paraná. 
en que los profesores se olvidaban de traer el material adaptado o hacían la exposición de forma que le era difícil seguir, los demás alumnos se posicionaban y llamaban la atención de los profesores. También se refiere con orgullo al profesor de Matemática y comenta que asistir a sus clases era su momento de satisfacción, por el hecho de darse cuenta que el profesor estaba muy empeñado que él aprendiera frecuentando cursos y trayendo recursos y materiales adaptados para las clases.

Como sugerencia para facilitar el aprendizaje, los participantes de la investigación fueron unánimes en considerar el diálogo entre el profesor y el alumno como el aspecto más importante. Expresaron que, si se anticipa al alumno ciego lo que será trabajado, el propio alumno tendrá condiciones de pensar junto al profesor en las estrategias. Según los alumnos, disminuir las barreras y aumentar la empatía entre profesor y alumno resulta un buen desempeño educacional.

\section{Finalizando}

La investigación destacó que el uso de herramientas y medios de comunicación adecuados aumentan las posibilidades de aprendizaje de los alumnos no videntes, en la medida donde permiten simular los aspectos de la realidad, interacción a distancia y sistematización de las informaciones. Aunque no haya sido objeto, demuestra que en una actividad en que estas herramientas y multimedia están utilizadas, los alumnos videntes también se benefician.

El rol del profesor en el proceso enseñanza-aprendizaje fue una vez más evidenciado a través de los discursos, cualquiera sea la situación, siendo fundamental en el caso de alumnos con deficiencia visual. Cuando la actuación del profesor ocurre en asociación con el profesor de la Sala de Recursos, las oportunidades de inclusión de los alumnos no videntes se amplían, ampliando también sus posibilidades de mejor aprender.

Siendo el profesional responsable por evaluar las dificultades y las potencialidades de cada alumno, organizar el Plan de Atención Individualizado para que cada uno de ellos tenga acceso a las Tecnologías Asistivas y aprenda a utilizar las herramientas que garantizan su autonomía en el aula de la educación regular, el profesor de la Sala de Recursos desempeña una función vital en este proceso. Siendo especializado, su 
mirada es para el más allá de la deficiencia, pues es necesario entender las singularidades de cada individuo y junto con él encontrar la mejor forma de aprendizaje.

En este proceso, la escuela y los profesores que tienen alumnos con deficiencia insertos en la educación regular tienen la posibilidad de rever su metodología de enseñanza y su práctica pedagógica, pues la inclusión no se restringe a minimizar barreras físicas y disponibilizar materiales y herramientas. Su desafío principal es minimizar las barreras actitudinales en lo que se refiere a las diferencias, pues ellas son ya visibles y no necesitan ser el centro de la discusión, y, principalmente, valorar las potencialidades de los alumnos.

\section{Referencias bibliográficas}

BRASIL. (1994) Declaração de Salamanca e Linha de Ação sobre Necessidades Educativas Especiais. Promulga sobre princípios, política e prática na área das necessidades educativas especiais. Brasília: Diário Oficial da União. Recuperado de http://portal. mec.gov.br/seesp/arquivos/pdf/salamanca.pdf.

- (2001) Decreto No 3.956 de 8 de outubro de 2001. Promulga a Convenção Interamericana para a Eliminação de Todas as Formas de Discriminação contra as Pessoas Portadoras de Deficiência. Brasília: Diário Oficial da União. Recuperado de http:// www.planalto.gov.br/ccivil_03/decreto/2001/d3956.htm.

- (2010) Decreto No 7084 de 27 de janeiro de 2010. Dispõe sobre os programas de material didático e dá outras providências. Brasília: Diário Oficial da União. Recuperado de http://www.planalto.gov.br/ccivil_03/_ato2007-2010/2010/decreto/D7084. htmimpressao.htm.

- (2010) Manual de orientação: Programa de Implantação de Sala de Recursos Multifuncionais. Brasília: Diário Oficial da União. Recuperado de http://www.oneesp. ufscar.br/orientacoes_srm_2010.pdf.

- (2010) Nota Técnica N 11 de 07 de maio de 2010. Orienta para a institucionalização da Oferta do Atendimento Educacional Especializado - AEE em Salas de Recursos Multifuncionais, implantadas nas escolas regulares. Brasília: Diário Oficial da União. Recuperado de portal.mec.gov.br/docman/maio-2010-pdf/5294-notatecnican112010.

- (2015) Lei Brasileira de Inclusão da Pessoa com Deficiência - Lei N 13.146, de 6 de julho de 2015. Brasília: Diário Oficial da União. Recuperado de http://www.planalto. gov.br/ccivil_03/_ato2015-2018/2015/lei/l13146.htm.

- (2013) Nota Técnica No 58 de 20 de maio de 2013. Orienta para usabilidade do livro didático digital acessível - Mecdaisy. Brasília: MEC/SECADI/DPEE. Recuperado de http:// portal.mec.gov.br/index.php?option=com_docman\&view=download\&alias=13294nt58-orient-livrodid-dig-acess-mecdaisy\&Itemid=30192. 
Aprender con otros sentidos: estrategias para la atención de alumnos con deficiencia visual

Quelen Silveira Coden y Nilson Marcos Dias Garcia

CHRISTOFARI, A. C.; BAPTISTA, C. R. (2012). Avaliação da aprendizagem: práticas e alternativas para a inclusão escolar. Revista Educação Especial, n. 44, v. 25, p. 383398. Recuperado de https://periodicos.ufsm.br/educacaoespecial/article/view/6533/ pdf.

CAMARGO, E. P. de. (2012) Saberes docentes para a inclusão do aluno com deficiência visual em aulas de Física. São Paulo: Editora Unesp.

- (2016) Inclusão e necessidade especial: compreendendo identidade e diferença por meio do ensino de física e da deficiência visual. São Paulo: Livraria da Física.

- (2017) Inclusão social, educação inclusiva e educação especial: enlaces e desenlaces. Revista Ciência \& Educação, n 1, v. 23, p. 1-6. Recuperado de http://www.scielo.br/ scielo.php?script=sci_arttext\&pid=S1516-73132017000100001.

CARVALHO, J. C. Q. (2015). Ensino de Física e deficiência visual: Possibilidades do uso do computador no desenvolvimento da autonomia de alunos com deficiência visual no processo de inclusão escolar. Tese de doutorado. Universidade de São Paulo, Brasil. Recuperado de http://www.teses.usp.br/teses/disponiveis/81/81131/tde21082015-173525/es.php.

COLL, C.; MACHESI, A.; PALACIOS J. (2004). Da linguagem da deficiência às escolas inclusivas. Desenvolvimento psicológico e educação: transtornos de desenvolvimento e necessidades educativas especiais. Porto Alegre: Artmed.

DIOGO, F. da C. S; SILVA, M. B. da (2013). Propostas de acessibilidade em ambientes digitais: um estudo teórico. In: $3^{0}$ Seminário de Informação em Arte -11 a 13 de novembro de 2013. Recuperado de http://redarterj.com/wp-content/uploads/2014/11/ PROPOSTAS-DE-ACESSIBILIDADE-EM-AMBIENTES-DIGITAIS.pdf.

FORGIARINI, R. R. (2012). A produção da autonomia no sujeito deficiente: contribuições da escola inclusiva. Revista Educação por Escrito -PUCRS, n. 2, v. 3, p. 51 63. Recuperado de http://revistaseletronicas.pucrs.br/ojs/index.php/porescrito/article/view/11241/8589.

MANTOAN, M. T. (2004). O direito de ser, sendo diferente, na escola. Revista CEJ, Brasília, n. 26, p. 36-44. Recuperado de http://www.jf.jus.br/ojs2/index.php/revcej/article/ viewFile/622/802.

MENEGUEL, S.M.; KREISH, C. (2009). Concepções de avaliação e práticas avaliativas na escola: entre possibilidades e dificuldades. Anais IX Congresso Nacional de Educação - PUCPR, p. 9819-9831. Recuperado de http://educere.bruc.com.br/arquivo/ pdf2009/3393_1920.pdf

PARANÁ (2016). Instrução $n^{0}$. 06/2016. Estabelece critérios para o Atendimento Educacional Especializado em Sala de Recursos Multifuncionais no Ensino Fundamental anos finais e Ensino Médio- Deficiência Visual. Recuperado de http://www.educacao. pr.gov.br/arquivos/File/instrucoes/instrucao062016sued.pdf.

VIGOTSKI, L. S. (1997). El niño ciego. In: Vigotski. Fundamentos de defectología. Havana: Editorial Pueblo y Educación, p. 74-87 (Obras escogidas, tomo V). 